\title{
Review Perkembangan PLTS di Provinsi Bali Menuju Target Kapasitas 108 MW Tahun 2025
}

\author{
A.A.G.A. Pawitra ${ }^{1}$, I.N.S. Kumara ${ }^{2}$, W.G. Ariastina $^{3}$ \\ [Submission: 09-09-2020, Accepted: 19-11-2020]
}

\begin{abstract}
The central government policy through RUEN targets Bali to use 108 MWp of solar energy by 2025. Bali as a small island of highly developed tourism destinations in Indonesia is considered to have the opportunity to exploit this potential. This research tries to review how the development of PV system in Bali through literature study and field observation. The results of this study indicate that the development of total PV system installed capacity in Bali to date has reached 3.71 MWp or $3.44 \%$ of the RUEN target. Based on data managed by the development of $\mathrm{PV}$ system in Bali in the last 14 years it increased an average of $265.18 \mathrm{kWp}$ or $7.14 \%$ annually. Until now the highest PV system capacity in Bali is in Karangasem Regency which has an installed PV system capacity of $1,106 \mathrm{kWp}$ or $29.79 \%$ of the total capacity in Bali. While the lowest capacity is in Jembrana Regency with an installed capacity of $10 \mathrm{kWp}$ or $0.27 \%$. PVsystem in Bali is used in a variety of applications, the largest capacity used for utilities is $\mathbf{5 8 . 6 4 \%}$, while the lowest is used for water pumps by $0.55 \%$. Based on the type of PV system, Bali is dominated by an on-grid PV system with an installed capacity of $3,225 \mathrm{kWp}$ or $87 \%$, while the lowest is a hybrid PV system with a capacity of $224 \mathrm{kWp}$ or $6 \%$ of the total capacity in Bali.
\end{abstract}

Intisari- Kebijakan pemerintah pusat melalui RUEN menargetkan Bali memanfaatkan energi matahari sebesar 108 MWp pada tahun 2025. Bali sebagai pulau kecil destinasi pariwisata yang sangat berkembang di Indonesia dinilai berpeluang dalam memanfaatkan potensi ini. Penelitian ini mencoba meninjau bagaimana perkembangan PLTS di Bali melalui studi pustaka dan obervasi lapangan. Hasil penelitian ini menunjukkan bahwa perkembangan total kapasitas PLTS terpasang di Bali sampai saat ini sudah mencapai 3,71 MWp atau 3,44\% dari target RUEN. Berdasarkan data yang dikelola perkembangan PLTS di Bali dalam 14 tahun terakhir meningkat rata-rata $265,18 \mathrm{kWp}$ atau $7,14 \%$ setiap tahunnya. Sampai saat ini kapasitas PLTS tertinggi di Bali terdapat di Kabupaten Karangasem yang memiliki kapasitas PLTS terpasang 1.106 kWp atau $29,79 \%$ dari total kapasitas di Bali. Sedangkan kapasitas terendah terdapat di Kabupaten Jembrana dengan kapasitas terpasang sebesar $10 \mathrm{kWp}$ atau $0,27 \%$. Sistem PLTS di Bali digunakan dalam berbagai macam aplikasi, kapasitas terbesar digunakan untuk utilitas sebanyak 58,64\%, sedangkan terendah digunakan untuk pompa air sebesar $0,55 \%$. Berdasarkan jenis PLTS, di Bali didominasi oleh sistem PLTS on-grid dengan kapasitas terpasang $3.225 \mathrm{kWp}$ atau $87 \%$, sedangkan terendah adalah sistem hybrid dengan kapasitas 224 kWp atau 6\% dari total kapasitas di Bali.

\footnotetext{
${ }^{1}$ Mahasiswa, Magister Teknik Elektro Universitas Udayana, Jl PB. Sudirman Denpasar, 80234: 0361-223797; e-mail: aripawitra@student.unud.ac.id)

2, 3 Pengajar, Magister Teknik Elektro Universitas Udayana, Jl PB. Sudirman Denpasar, 80234 INDONESIA: 0361-223797; e-mail: $\quad$ satya.kumara@unud.ac.id,
}

A.A.G.A Pawitra: Review Perkembangan di Provinsi Bali...
Kata Kunci- Energi Terbarukan, PLTS, Energi Bersih, Kebijakan Energi, Pariwisata Hijau Bali.

\section{Pendahuluan}

Letak geografis Indonesia yang dilalui oleh garis Equator memberikan banyak keuntungan, salah satunya memiliki intensitas penyinaran matahari yang baik sepanjang tahun. Berdasarkan data dari Dewan Energi Nasional (DEN), potensi energi matahari di Indonesia mencapai rata-rata $4,8 \mathrm{kWh} / \mathrm{m}^{2}$ /hari, setara dengan $112.000 \mathrm{GWp}$ jika dibandingkan dengan potensi luasan lahan di Indonesia atau sepuluh kali lipat dari potensi Jerman dan Eropa [1]. Dengan besarnya potensi tersebut, sudah selayaknya pengembangan Pembangkit Listrik Tenaga Surya (PLTS) menjadi prioritas. Selain itu teknologi PLTS juga terus berkembang, efisiensi modul surya yang semakin tinggi dan biaya yang semakin murah seharusnya lebih mudah dalam merealisasikan pemanfaatan potensi energi surya.

Melihat potensi yang besar tersebut pemerintah mengambil tindakan dengan membuat Kebijakan Energi Nasional (KEN) yang menjadi dasar lahirnya Rencana Umum Energi Nasional (RUEN). RUEN merupakan kebijakan Pemerintah mengenai rencana pengelolaan energi tingkat nasional yang menjadi penjabaran dan rencana pelaksanaan KEN yang bersifat lintas sektor untuk mencapai sasaran KEN. Target KEN dalam meningkatkan penggunaan Energi Baru Terbarukan (EBT) pada tahun 2025 sebesar $23 \%$ atau sebesar 92,2 MTOE, dimana untuk penggunaan energi surya sendiri ditargetkan sebesar 6,5 GW. Namun saat ini secara nasional penggunaan PLTS masih di angka $137 \mathrm{MW}$ [2].

Menurut RUEN, Provinsi Bali ditargetkan mengembangkan PLTS sebesar $8,62 \%$ atau 108,2 MW dari total potensinya sebesar 1.254 MW [3]. Melanjutkan rencana energi nasional pemerintah daerah di masing-masing provinsi diharuskan menyusun Rencana Umum Energi Daerah (RUED). Saat ini Provinsi Bali sudah rampung dalam menyusun RUED, namun statusnya masih dalam pembahasan oleh legislatif. Disebutkan juga bahwa Provinsi Bali pada tahun 2025 hanya mampu memanfaatkan EBT sebanyak $11,15 \%$ dan $20,50 \%$ pada tahun 2050 [4].

Melihat kondisi tersebut pemerintah pusat terus berupaya, salah satunya dengan mengeluarkan Peraturan Menteri Energi Sumber Daya Mineral (ESDM) No. 49 Tahun 2018 tentang penggunaan PLTS Atap (Rooftop) untuk seluruh pelanggan PT. PLN yang berminat menghemat biaya tagihan listrik setiap bulannya. Peraturan tersebut dibuat untuk menarik minat masyarakat atau pihak swasta agar mulai beralih menggunakan sumber energi EBT khususnya PLTS atap. Sejalan dengan pemerintah pusat, Pemerintah Provinsi Bali

$$
\text { p-ISSN:1693 - 2951; e-ISSN: 2503-2372 }
$$


membuat kebijakan yang membahas penggunaan EBT melalui Pergub No. 45 Tahun 2019 tentang Bali Energi Bersih. Berdasarkan laporan dari Center for Community Based Renewable Energy (CORE) dan Greenpeace Indonesia menjelaskan bahwa Provinsi Bali memiliki potensi yang sangat besar dalam memanfaatkan PLTS atap sebagai sumber energi listrik berbasis energi bersih. Potensi PLTS atap yang dimiliki wilayah Bali selatan yaitu empat kabupaten yang biasa disebut SARBAGITA saja berjumlah minimal 49,5 MWp dan maksimal 129,78 MWp [5].

Perkembangan PLTS di Bali sampai saat ini terbilang cukup baik, disebabkan pengguna PLTS atap dari tahun ke tahun mengalami peningkatan. Pada tahun lalu peningkatan penggunaan PLTS atap di Bali mencapai 49 unit yang memiliki kapasitas total sebesar $470 \mathrm{kWp} \mathrm{[5].} \mathrm{Jika} \mathrm{kita}$ bandingkan dengan target yang harus dicapai pada tahun 2025, peningkatan ini tergolong lambat. Karena sampai saat ini total kapasitas PLTS yang terpasang di Bali baru mencapai 3 - 4 MWp. Angka tersebut masih sangat jauh dari target, sehingga perlu percepatan dalam pengaplikasiannya.

Salah satu upaya dalam mempercepat perkembangan penggunaan PLTS di Bali adalah dengan cara mengulas perkembangannya agar bisa memacu pemangku kepentingan untuk melakukan percepatan pembangunan agar bisa mencapai target yang sudah ditetapkan. Maka dari itu penelitian ini akan mengulas perkembangan PLTS di Bali sampai saat ini. Penelitian ini dilakukan dengan mengumpulkan data-data dari semua pemangku kepentingan yang berhubungan dengan PLTS. Data tersebut akan dikelola dan dianalasis sehingga menghasilkan data perkembangan yang nantinya bisa dijadikan acuan untuk menentukan kebijakan selanjutnya.

\section{Pembangkit Listrik Tenaga Surya}

Pembangkit Listrik Tenaga Surya (PLTS) merupakan suatu teknologi pembangkit yang mengkonversikan energi foton dari energi cahaya matahari menjadi energi listrik. Konversi ini terjadi pada Photovoltaic (PV) modul yang terdiri dari sel surya. Sel surya merupakan lapisan-lapisan tipis dari silicon (Si) murni dan bahan semikonduktor lainnya. Apabila bahan tersebut mendapat energi foton, akan mengeksitasi elektron dari ikatan atomnya menjadi elektron yang bergerak bebas dan akhirnya akan mengeluarkan tegangan listrik arus searah [6].

Komponen PLTS terdiri dari beberapa komponen utama, pertama adalah modul/panel surya yang berfungsi menangkap energi surya dan mengubah menjadi energi listrik. Komponen berikutnya adalah inverter yang berfungsi sebagai perubah tegangan listrik DC yang dihasilkan modul surya menjadi tegangan listrik AC. Jika PLTS yang dibangun sistem off-grid, maka memerlukan komponen tambahan seperti solar charge controller dan baterai. Solar charge controller berfungsi sebagai pengatur arus listrik yang masuk ke baterai, agar arus yang tersuplai ke baterai tidak berlebihan. Sedangkan baterai berfungsi sebagai tempat penyimpanan energi listrik yang dihasilkan modul surya [7]. Selain itu komponen utama yang tak kalah pentingnya adalah penyangga modul surya, dimana tipe penyangga yang digunakan oleh suatu sistem PLTS mampu mempengaruhi produksi energi listriknya.

Produksi energi listrik yang dihasilkan oleh PLTS dipengaruhi oleh beberapa faktor. Pengaruh yang paling kuat adalah cuaca, dimana sumber energi utama yang diperlukan oleh PLTS dalam memproduksi energi listrik adalah sinar matahari (energi surya). Faktor berikutnya yang mempengaruhi adalah suhu, hal ini disebabkan oleh tingkat sensitifitas dari sel surya pada modul surya. Semakin suhu sekitar PLTS meningkat maka efisiensi dari modul surya akan berkurang yang mempengaruhi produksi energi dari PLTS. Faktor lainnya adalah posisi dari PLTS tersebut, agar produksi energi PLTS optimum perlu diperhatikan posisi dan orientasi dari modul surya [8]. Karena jika disekitar PLTS terdapat pohon yang pada saat siang hari menghasilkan bayangan yang mengenai modul surya, maka modul tersebut tidak bisa menangkap energi foton sinar matahari dengan maksimum karena terhalang bayangan dari pohon.

Setiap sistem pasti memiliki kelebihan dan kekurangan, begitu juga dengan sistem PLTS. Kelebihan dari PLTS yang utama adalah sumber energi yang tidak akan pernah habis dan diperoleh secara gratis tidak menimbulkan polusi, dan ramah lingkungan. Bila dibandingkan pembangkit listrik energi fosil, pengoperasian dan pemeliharaan dari PLTS sangat kecil dan memiliki resiko kerja yang rendah. Namun kekurangannya terdapat pada nilai investasi awal yang tinggi, sehingga menghasilkan energi listrik yang mahal jika dibandingkan dengan biaya produksi energi listrik per $\mathrm{kWh}$ dari pembangkit listrik lain yang bersumber dari energi fosil. Selain itu PLTS sangat bergantung pada cuaca, jadi kurang efektif dibangun pada wilayah yang memiliki intensitas hujan yang tinggi [9].

\section{BAHAN DAN METODOLOGI}

Penelitian ini bertujuan untuk mengetahui sampai mana perkembangan dari pemanfaatan PLTS di Bali dalam mencapai target RUEN sebesar 108 MWp. Penelitian akan dilakukan dengan beberapa tahap yang digambarkan dalam skematik berikut:

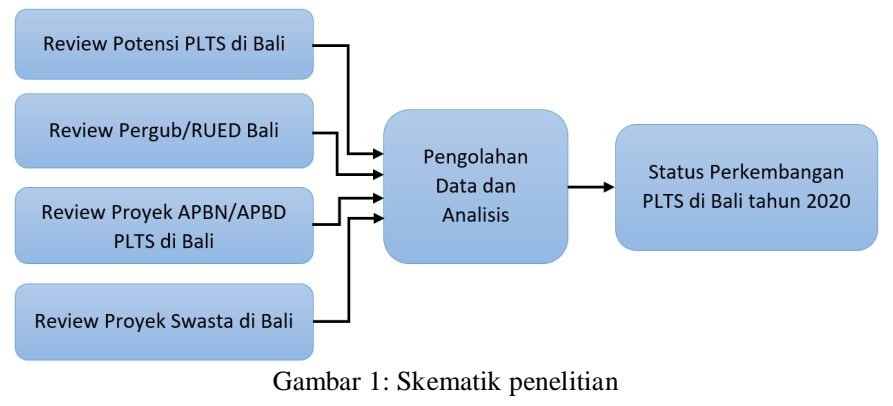

Berdasarkan skematik diatas, tahap awal dari penelitian ini adalah pengumpulan data. Data yang dikumpulkan bersumber dari berbagai jenis data, berupa dokumen maupun wawancara dengan pihak terkait. Data-data tentang perkembangan PLTS di Bali diperoleh dari artikel jurnal ilmiah, publikasi konferensi, dokumen/berita resmi pemerintah pusat/daerah, berita media masa, situs integrator/EPC PLTS nasional, dan observasi ke lapangan. Survei on-line dilakukan menggunakan mesin pengindeks/mesin pencari seperti Google Scholar, Neliti.com, IEEEXplorer, dan Researchgate, serta sumber lain.

Setelah data terkumpul, tahap selanjutnya adalah melakukan ulasan mendalam terhadap data tersebut. Pertama data yang diulas adalah potensi PLTS, bagian ini akan menjelaskan seberapa besar potensi yang dapat dicapai dalam memanfaat-kan energi surya. Kedua akan membahas terusan 
Majalah Ilmiah Teknologi Elektro, Vol. 19, No. 2, Juli - Desember 2020

DOI: https://doi.org/10.24843/MITE.2020.v19i02.P09

kebijakan pemerintah pusat kepada pemerintah daerah melalui Pergub/RUED guna mempercepat pengembangan PLTS di Bali agar mampu mencapai target yang sudah ditetapkan dalam RUEN. Ketiga pembahasan terhadap proyek PLTS yang sudah dibangun pemerintah di Bali. Terakhir membahas Proyek PLTS yang sudah dibangun oleh pihak swasta. Selanjutnya data dan ulasan tersebut akan dilakukan pengelolaan dan analisis. Setelah proses pengelola-an dan analisis data menghasilkan sebuah kesimpulan yang menyatakan bagaimana status perkembangan PLTS di Bali pada tahun 2020.

\section{HASIL DAN PEMBAHASAN}

Target pemerintah Indonesia yang tertuang dalam RUEN jelas menargetkan Provinsi Bali mampu memenuhi kontribusi penggunaan EBT khususnya PLTS secara nasional sebesar 108 MWp pada tahun 2025. Angka tersebut masih tergolong wajar mengingat potensi yang dimiliki Provinsi Bali sebesar 1.254 MWp [3]. Saat ini PLTS yang sudah beroperasi di Bali sudah cukup banyak, berawal dari tahun 2007 yang dibangun di Nusa Penida Kabupaten Klungkung. PLTS berkapasitas $16,6 \mathrm{kWp}$ yang dimanfaatkan untuk sistem pemurnian air Reverse Osmosis (RO). PLTS yang dibangun oleh pemerintah ini menggunakan modul surya berkapasitas $130 \mathrm{Wp}$ yang berjumlah 2 x 64 unit. Sistem PLTS ini juga menggunakan sistem baterai yang berkapasitas 2 × $2000 \mathrm{Ah}$ dan penyangga modul surya tipe solar tracker yang berfungsi mengikuti orientasi matahari. Sistem Solar Powered Reverse-Osmosis Water Filtration System yang dibangun ini mampu menghasilkan 4.000 liter air bersih yang layak minum untuk keperluan masyarakat Nusa Penida [10].

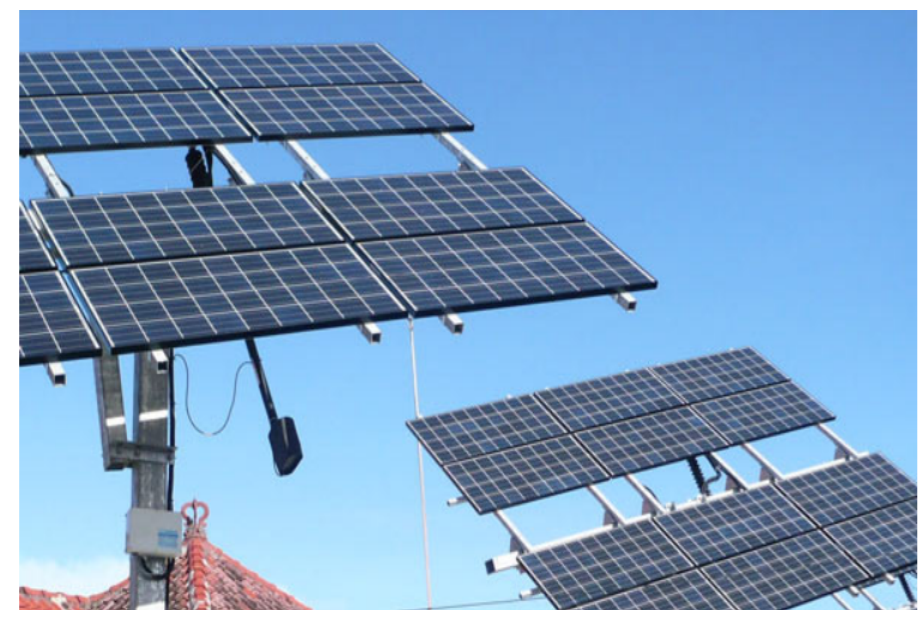

Gambar 2: Sistem PLTS Nusa Penida kapasitas 16,6 kWp [10]

Tahun berikutnya Nirwana Villas Gianyar mengawali inisiatif sebagai bangunan ramah lingkungan "Green Building" dengan membangun PLTS dengan kapasitas 2,7 kWp. Sistem PLTS ini menggunakan modul surya kapasitas $180 \mathrm{Wp}$ yang berjumlah 15 unit dan menggunakan penyangga tipe Solar Tracker sebanyak dua unit. Pada bangunan ini juga menggunakan Solar Thermal Hot Water System sebanyak tiga unit yang masing-masing unitnya berkapasitas 300 liter sebagai sumber untuk memenuhi kebutuhan air panas [10].

A.A.G.A Pawitra: Review Perkembangan di Provinsi Bali...
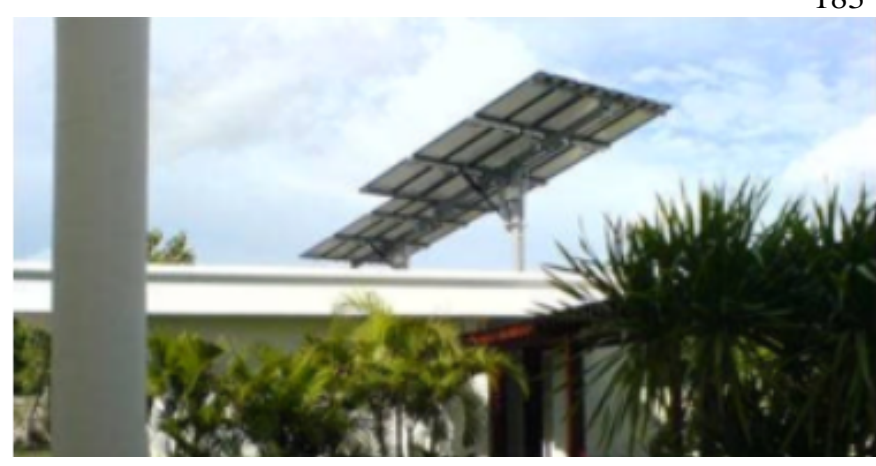

Gambar 3: Sistem PLTS Nirwana Villas Gianyar kapasitas 2,7 kWp [10]

Selanjutnya proyek PLTS yang ada di Bali terdapat di daerah Sanur yang dibangun pada tahun 2012. Botha Villas membangun sistem PLTS off-grid berkapasitas $5,76 \mathrm{kWp}$ dengan menggunakan modul surya jenis monocrystalline kapasitas $240 \mathrm{Wp}$ sebanyak 24 unit. Sistem ini dilengkapi baterai sebagai penyimpan energi listrik yang berkapasitas 1.200 Ah. Penyangga yang digunakan pada PLTS ini berjenis Solar Tracker dengan tujuan memaksimalkan produksi energi listriknya. Selain sistem PLTS untuk keperluan energi listrik sehari-hari, bangunan ini juga menggunakan sumber energi ramah lingkungan lainnya, yaitu Solar Pool Pump dan Solar Hot Water System [10].

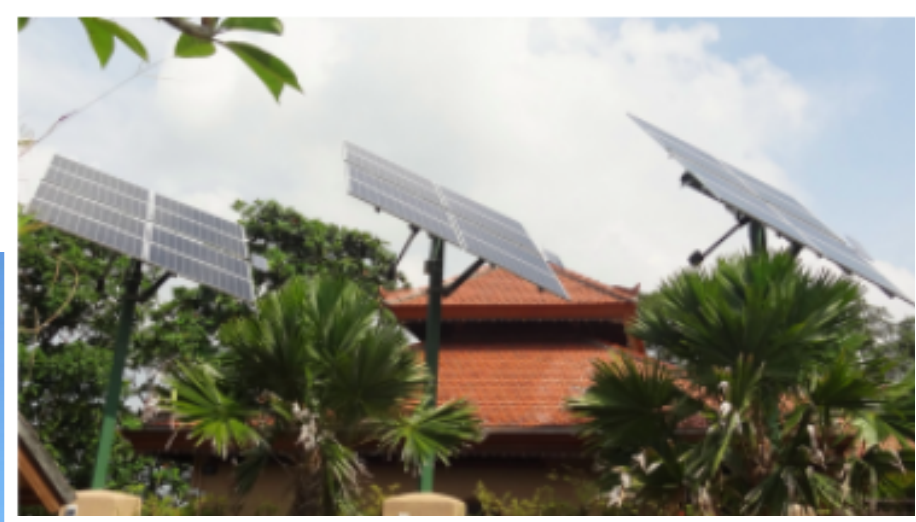

Gambar 4: Sistem PLTS Botha Villas Sanur kapasitas 5,76 kWp [10]

Perkembangan PLTS di Bali pada tahun 2013 berkembang cukup signifikan yang disebabkan oleh program pemerintah pusat dalam memacu target bauran energi terbarukan. Provinsi Bali mendapatkan banyak hibah PLTS dari pemerintah pusat yang bertujuan sebagai percontohan pemanfaatan sumber energi terbarukan di daerah. Pemerintah pusat membangun PLTS dengan kapasitas total 2,1 MWp. Pembangunan terbesar berada di kabupaten Karangasem dan Bangli yang masingmasing memiliki kapasitas $1 \mathrm{MWp}$. Sisanya terbangun tujuh sistem PLTS di beberapa wilayah kabupaten Karangasem, Bangli, dan Klungkung yang masing-masing memiliki kapasitas $15 \mathrm{kWp}$ [1].

Sistem PLTS 1 MWp Karangasem dan Bangli memiliki sistem on-grid, yang mana langsung terkoneksi dengan jaringan PLN. Sedangkan PLTS $15 \mathrm{kWp}$ yang berada di desa Datah, Yeh Mampeh, Cegi, Sekartaji Nusa Penida, Tianyar Barat menggunakan sistem off-grid, dimana energi listrik
p-ISSN:1693 - 2951; e-ISSN: 2503-2372 
yang dihasilkan langsung disalurkan ke konsumen atau disimpan ke baterai untuk digunakan pada malam hari.

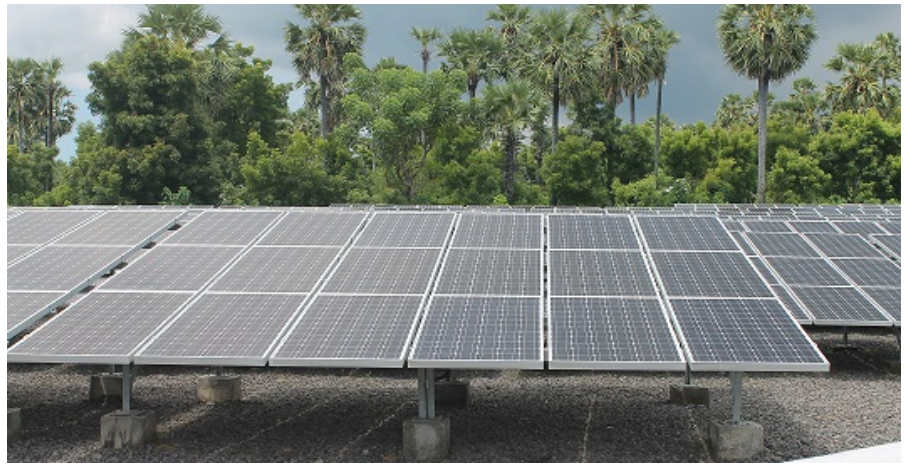

Gambar 5: Sistem PLTS On-grid Karangasem kapasitas 1 MWp

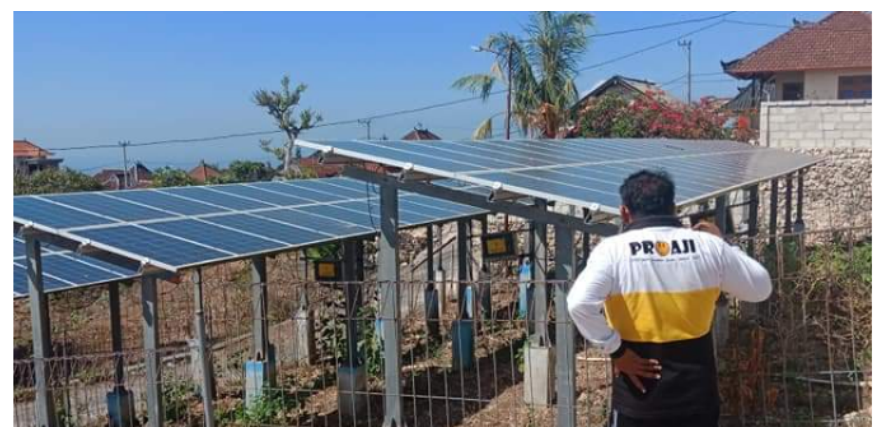

Gambar 6: Sistem PLTS Off-grid Desa Sekartaji kapasitas 15 kWp [16]

Selain pihak pemerintah pihak swasta juga gencar membangun pembangkit energi terbarukan, karena komitmen pemilik untuk mengembangkan eco tourism di Bali seperti yang dilakukan oleh Munduk Plantation Resort yang berlokasi di kabupaten Buleleng. Sistem PLTS yang digunakan berkapasitas $10 \mathrm{kWp}$ on-grid yang dibangun pada tahun 2014 . Sejalan dengan Munduk Resort, Suarga Resort Padang Padang juga menggunakan PLTS untuk sumber energi alternatif. Kapasitas PLTS sebesar $70 \mathrm{kWp}$ off-grid mampu memenuhi kebutuhan kantor dan beberapa unit villa sepanjang hari, karena dilengkapi dengan baterai. Komitmen pengelola terhadap penggunaan EBT juga dicerminkan dari penggunaan Hot Water Solar System yang berkapasitas 4.500 liter dan empat unit Solar Pool Pumps untuk memenuhi suplai kolam berenang sebesar $250 \mathrm{~m}^{3}$ [11].

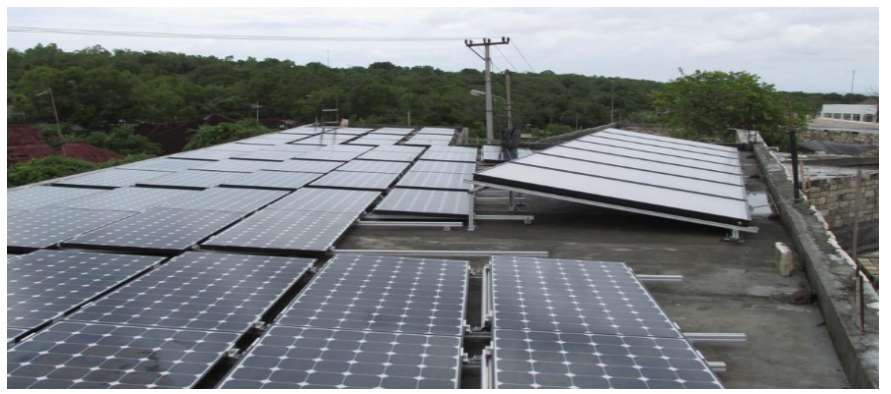

Gambar 7: Sistem PLTS Off-grid Suarga Resort kapasitas 70 kWp [11]

Proyek PLTS milik swasta lainnya terdapat di daerah Pejeng Gianyar, pemiliknya adalah Mr. Boogaart. Rumah yang bergaya villa khas Bali tersebut dipasang modul surya sebanyak 10 unit tipe Polycrystalline yang berkapasitas 240
Wp. Total kapasitas PLTS sebesar 2,4 kWp tersebut merupakan tipe PLTS on-grid dibangun pada tahun 2015 [10]. Pada tahun yang sama salah satu restoran ternama di Ubud juga memannfaatkan PLTS sebagai sumber energi alternatif. Restoran Locavore memasang sistem PLTS on-grid berkapasitas $8 \mathrm{kWp}$.

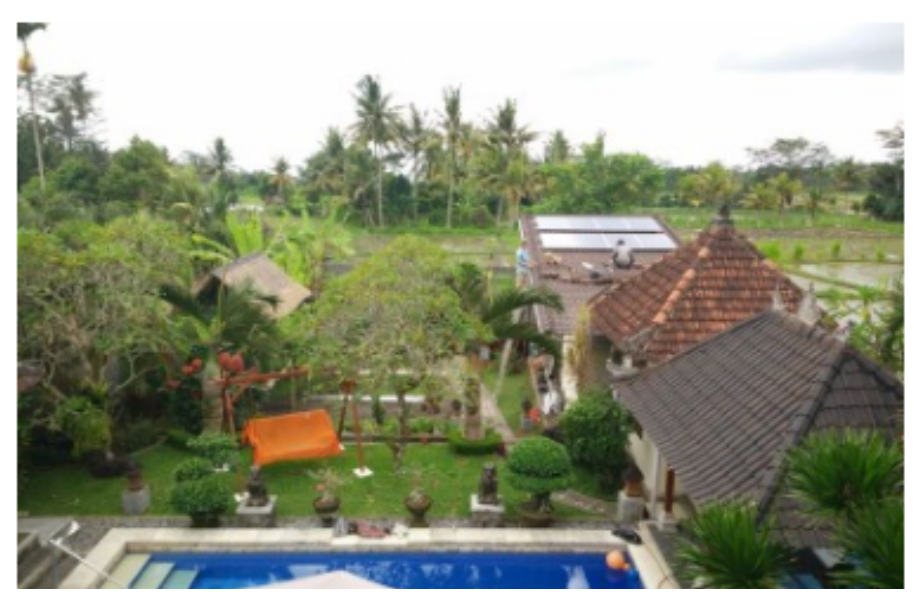

Gambar 8: Sistem PLTS on-grid Boogaart Residence kapasitas 2,4 kWp [10]

Villa Elena yang berlokasi di daerah pariwisata Sanur yang masuk wilayah administrasi kota Denpasar memiliki sistem PLTS yang dibangun pada tahun 2016. Sistem PLTS yang digunakan jenis on-grid yang memiliki kapasitas 10,2 $\mathrm{kWp}$, disusun dari 34 unit modul surya tipe Polycrystalline berkapasitas masing-masing $300 \mathrm{Wp}$ [10]. Sistem ini juga dilengkapi dengan fasilitas monitoring yang terintegrasi langsung ke jaringan internet. Berdasarkan dari sistem monitoring disampaikan PLTS ini sudah memproduksi energi listrik sebesar 46,7 MWh sampai saat ini.

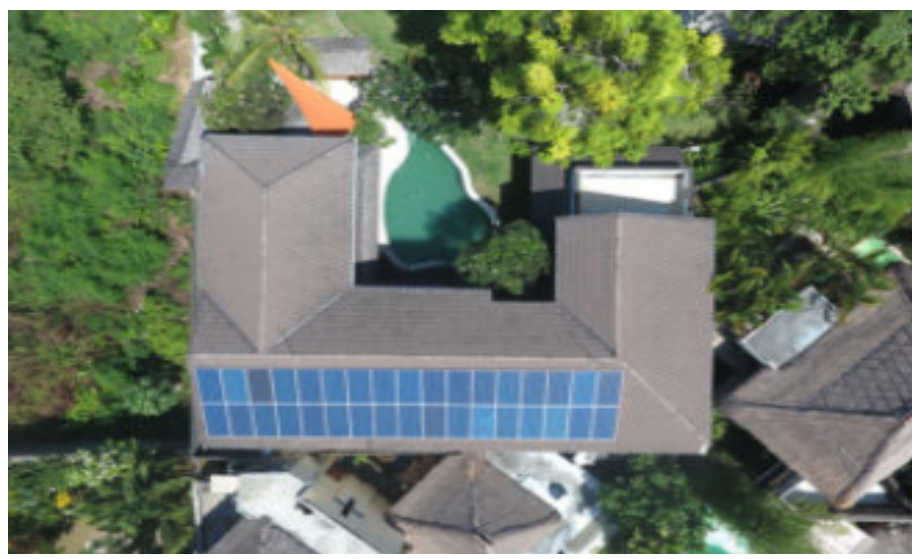

Gambar 9: Sistem PLTS on-grid Elena Villa kapasitas 10,2 kWp [10]

Identik dengan sistem PLTS Elena Villa, Ubud Yoga Centre memiliki PLTS on-grid berkapasitas 20,4 kWp. Ubud Yoga Centre merupakan tempat melakukan aktifitas yoga yang berada di Kecamatan Ubud Kabupaten Gianyar. Sistem PLTS ini disusun dari 68 unit modul surya tipe polycrystalline dengan kapasitas masing-masing 300 Wp yang diaplikasikan pada atap bangunan [10]. Sistem ini juga dilengkapi dengan sistem monitoring berbasis cloud yang bisa diakses dari mana saja. Sampai saat ini sistem PLTS sudah memproduksi energi listrik sebanyak 85,7 MWh dari tahun 2016. 


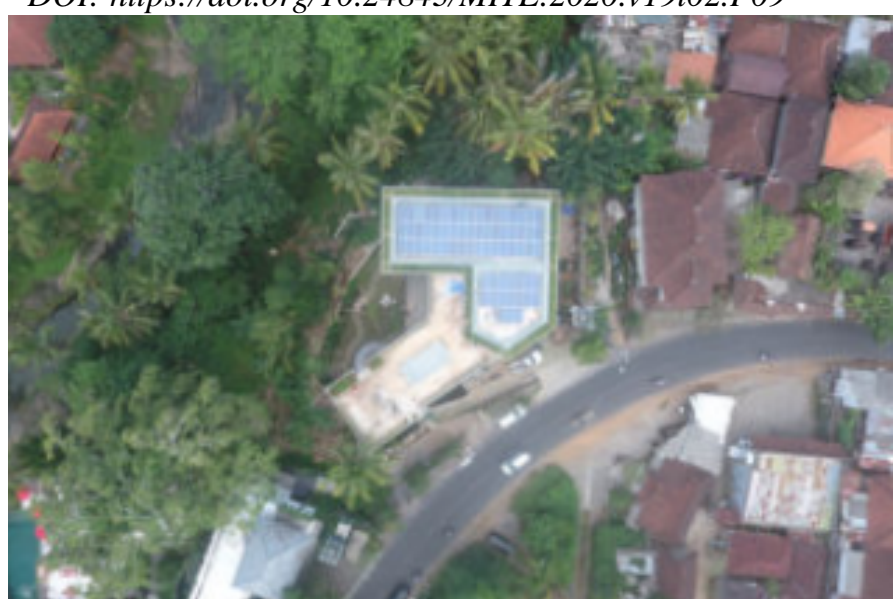

Gambar 10: PLTS on-grid Ubud Yoga Centre kapasitas 20,4 kWp [10]

Pada tahun yang sama pemerintah Provinsi Bali meresmikan penggunaan PLTS atap di kantor Gubernur Bali yang berkapasitas $158 \mathrm{kWp}$. Proyek ini merupakan hasil kerja sama dengan Kementrian Energi Sumber Daya dan Mineral (ESDM) dalam pengembangan penggunaan EBT agar mampu mencapai target. Sistem PLTS yang digunakan memiliki tipe on-grid yang disusun dari 624 unit modul surya yang masingmasing berkapasitas $255 \mathrm{Wp}$ yang dibangun di atas lapangan tenis milik pemerintah. Berdasarkan penelitian yang sudah dilakukan PLTS ini berpotensi menghasilkan energi listrik sebesar 249.764 kWh per tahun [12].

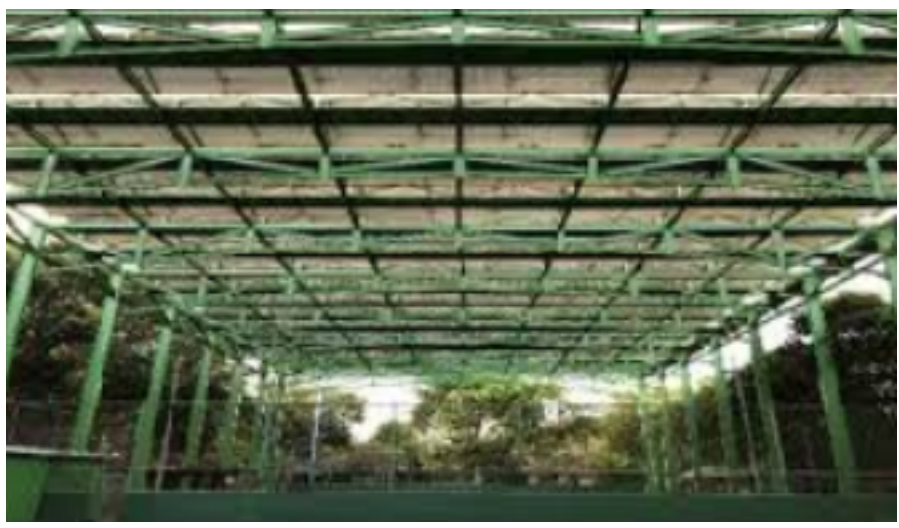

Gambar 11: PLTS on-grid Kantor Gubernur Bali kapasitas 158 kWp [12]

Kelebihan dari PLTS selain mengurangi polusi dan ramah lingkungan adalah potensi keuntungan yang diperoleh oleh pengelola. Salah satu perusahaan yang bergerak di bidang ini adalah PT. Terregra Asia Energy Tbk. Perusahaan ini bergerak dibidang penjualan energi listrik yang berasal dari pembangkit listrik EBT, konsepnya adalah business to business. Proyek pertama di Indonesia terdapat di Provinsi Bali, yaitu wahana bermain air Waterboom yang terletak di Kuta. Sistem PLTS yang dibangun oleh PT Terregra ini berkapasitas 156,09 $\mathrm{kWp}$, produksi energi listrik yang dihasilkan dijual ke Waterboom Bali dengan kontrak kerja sama selama 20 tahun [13]. Konsep bisnis seperti ini perlu disosialisasikan agar lebih banyak investor atau pelaku usaha yang berminat, hal ini akan berdampak pada percepatan pengembangan pemanfaatan PLTS di Indonesia.

A.A.G.A Pawitra: Review Perkembangan di Provinsi Bali...

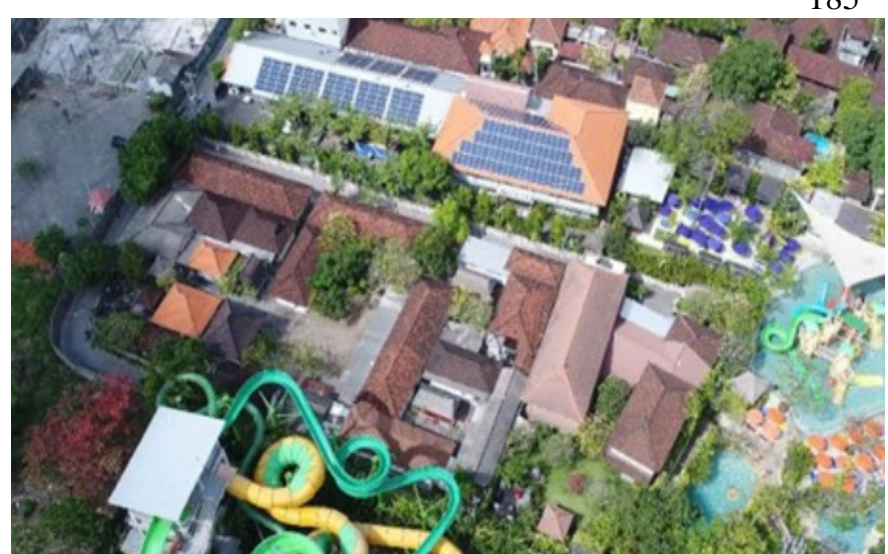

Gambar 12: PLTS on-grid Waterboom Bali kapasitas 156,09 kWp [13]

Perguruan tinggi merupakan salah satu dari pemangku kepentingan dalam pengembangan pemanfaatan EBT. Pemerintah pusat melalui kementrian ESDM pada tahun 2016 bekerja sama dengan Universitas Udayana (UNUD) dalam bidang energi terbarukan dengan membangun sebuah sistem smart micro grid untuk keperluan sebuah gedung milik UNUD. Sistem PLTS dibangun di atap gedung DH yang berada di kawasan Fakultas Teknik UNUD Jimbaran. Kapasitas PLTS yang dibangun sebesar 26,4 kWp yang disusun dari 80 unit modul surya kapasitas $330 \mathrm{Wp}$. Sistem PLTS ini merupakan sistem hibrida, karena sistem ini juga memiliki sumber energi dari Pembangkit Listrik Tenaga Bayu (PLTB) dan tersambung ke jaringan PLN. Sistem mulai beroperasi pada tahun 2017, mampu memproduksi energi listrik sebesar 38,95 kWh dalam setahun [14].

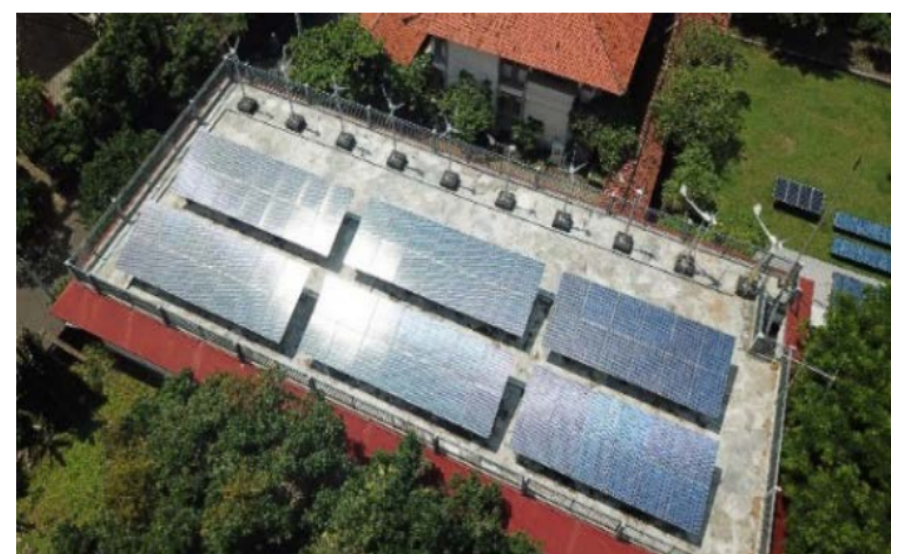

Gambar 13: PLTS smart micro grid UNUD kapasitas 26,4 kWp [14]

Pemangku kepentingan dari pihak pemerintah yang bergerak di bidang penyedia kelistrikan tidak mau ketinggalan dengan membangun PLTS atap baru. Anak perusahaan dari PLN, Indonesia Power Bali baru saja meresmikan PLTS atap berkapasitas total $226 \mathrm{kWp}$ [15]. Pembangunan dilakukan tahun 2019 yang dibangun di dua lokasi. Lokasi pertama dibangun di atap pembangkit listrik milik Indonesia Power yang terletak di Pesanggaran dengan kapasitas terpasang 130 kWp. Lokasi berikutnya dibangun di pembangkit listrik Indonesia Power yang terletak di Pemaron yang memiliki kapasitas $96 \mathrm{kWp}$.

p-ISSN:1693 - 2951; e-ISSN: 2503-2372

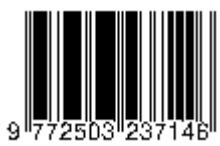




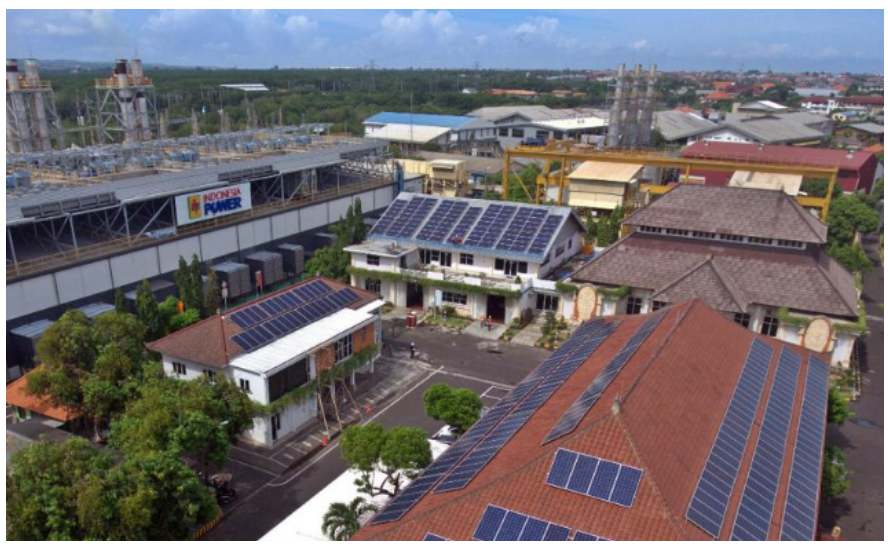

Gambar 14: PLTS on-grid Indonesia Power kapasitas 136 kWp [15]

Pelaksana proyek PLTS atap di Indonesia Power ini dilaksanakan oleh PT. Indo Tenaga Hijau yang merupakan anak perusahaan dari Indonesia Power. Indonesia Power selaku perusahaan yang bergerak dibidang pembangkit listrik milik negara perlu lebih banyak melakukan pengembangan dalam memanfaatkan sumber energi terbarukan. Hal ini bertujuan untuk meyakinkan masyarakat bahwa pemanfaatan sumber EBT atau PLTS dapat memberikan menguntungkan dalam berbagai aspek.

Dalam upaya mengembangkan pembangkit listrik energi terbarukan sesuai dengan arahan pemerintah pusat yang bersinergi dengan berbagai pemangku kepentingan, Provinsi Bali berkembang cukup baik. Berdasarkan data yang sudah diperoleh dari berbagai sumber, perkembangan PLTS di Bali dapat dilihat pada tabel berikut:

TABEL I

PERKEMBANGAN PLTS Di BALI

\begin{tabular}{cr}
\hline Tahun & \multicolumn{1}{c}{ Kapasitas } \\
PLTS $(\mathbf{k W p})$
\end{tabular}

Berdasarkan tabel diatas dapat dilihat perkembangan terbesar terjadi pada tahun 2013, pada tahun tersebut pembangunan PLTS di Bali bertambah sebesar $2.141 \mathrm{kWp}$. Perkembangan pesat pada saat itu merupakan hibah dari pemerintah pusat dalam rangka menetapkan Provinsi Bali sebagai daerah percontohan pemanfaatan PLTS berskala besar. Sampai saat ini jumlah kapasitas PLTS terpasang yang sudah beroperasi di Bali mencapai 3.712,53 kWp.

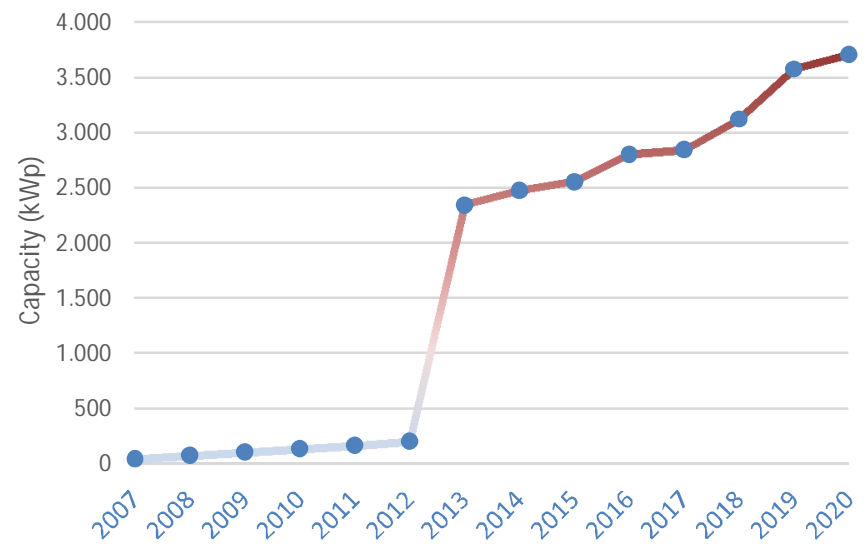

Gambar 16: Pertumbuhan kapasitas PLTS terpasang di Bali

Grafik diatas menyimpulkan bahwa perkembangan PLTS di Bali cukup baik dengan pertumbuhan kapasitas PLTS ratarata $265,18 \mathrm{kWp}$ atau 7,14 \% per tahun dalam kurun waktu 14 tahun. Jika dibandingkan dengan target RUEN sebesar 108 MWp pada tahun 2025, kapasitas terpasang di Bali saat ini baru mencapai 3,44\%. Jika ingin mencapai target RUEN dalam sisa waktu yang sudah ditentukan, maka pemangku kepentingan harus memacu percepatan pemanfaatan yang disajikan dalam diagram berikut:

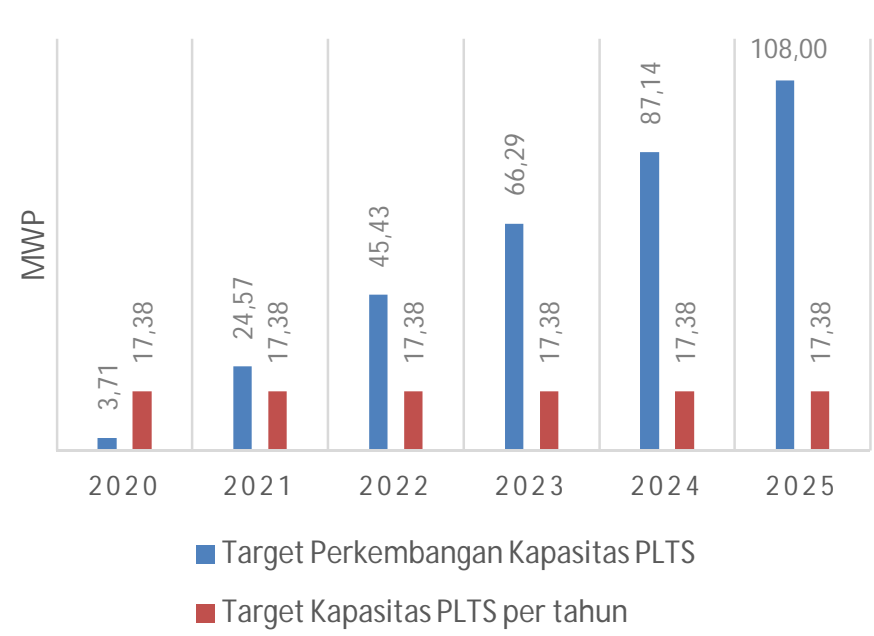

Gambar 17: Target pertumbuhan kapasitas PLTS terpasang di Bali

Target pembangunan PLTS di Bali agar mampu mencapai target yang sudah ditentukan RUEN per tahunnya adalah sebesar 17,38 MWp. Dengan penambahan pembangunan PLTS sebesar 16,09\% per tahun dari tahun 2020, maka pada tahun 2025 target penggunaan energi listrik bertenaga surya di Bali sebesar 108 MWp bisa dicapai.

Strategi percepatan pembangunan PLTS di Bali perlu dilakukan secara merata agar target bisa tercapai. Peran pemerintah daerah dalam hal memberi contoh dan sosialisasi perlu ditingkatkan. Hal ini tidak mudah mengingat setiap daerah memiliki karakter dan kemampuan yang berbeda. Peta komposisi pemanfaatan PLTS di Provinsi Bali sampai saat ini dapat dilihat pada diagram berikut: 
Majalah Ilmiah Teknologi Elektro, Vol. 19, No. 2, Juli-Desember 2020

DOI: https://doi.org/10.24843/MITE.2020.v19i02.P09

TABEL III

KAPASITAS PLTS TERPASANG DI KABUPATEN/KOTA DI BALI

\begin{tabular}{|c|c|c|}
\hline No. & Kabupaten & $\begin{array}{l}\text { Kapasitas PLTS } \\
\text { terpasang (kWp) }\end{array}$ \\
\hline 1 & Denpasar & 471,02 \\
\hline 2 & Badung & 827,41 \\
\hline 3 & Gianyar & 50,02 \\
\hline 4 & Tabanan & 50,48 \\
\hline 5 & Klungkung & 76,64 \\
\hline 6 & Karangasem & $1.106,00$ \\
\hline 7 & Bangli & $1.015,00$ \\
\hline 8 & Buleleng & 106,00 \\
\hline \multirow[t]{2}{*}{9} & Jembrana & 10,00 \\
\hline & & $3.712,57$ \\
\hline
\end{tabular}

Berdasarkan tabel diatas dapat disimpulkan bahwa sebaran PLTS terpasang di Provinsi Bali terbesar ada di Kabupaten Karangasem dengan kapasitas terpasang 1.106 MWp. Sedangkan terkecil ada terdapat di Kabupaten Jembrana dengan kapasitas terpasang $10 \mathrm{kWp}$. Jika dikonversi ke persentase dapat dilihat pada diagram berikut:

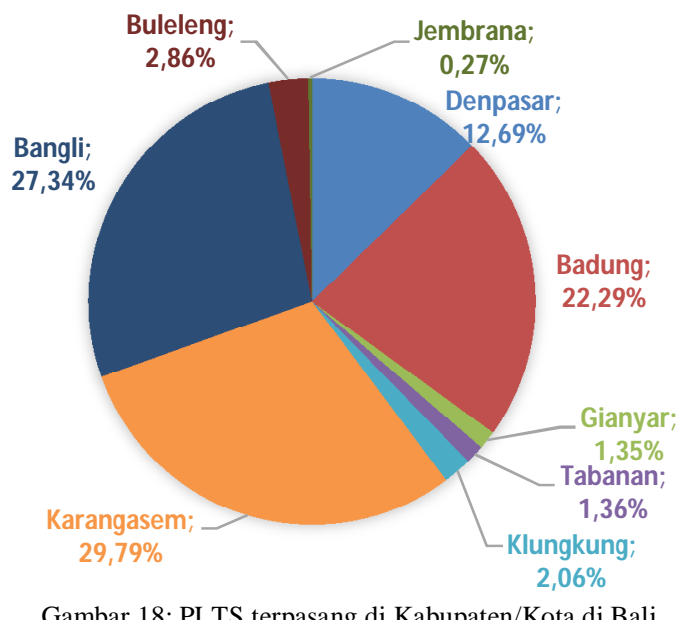

Berdasarkan diagram diatas komposisi PLTS terpasang di Provinsi Bali tidak merata, perbedaan kapasitas terpasang pada masing-masing kabupaten masih cukup jauh. Kabupaten Karangasem dan Bangli mendapatkan hibah PLTS dengan kapasitas masing-masing $1 \mathrm{MWp}$ yang mana ini merupakan PLTS dengan kapasitas terbesar di Bali. Jika kita asumsikan tanpa hibah tersebut, maka perkembangan PLTS tertinggi terdapat di Kabupaten Badung. Hal ini disebabkan oleh posisi Kabupaten Badung sebagai tonggak pariwisata Bali yang menjadikan Badung target investasi atau rumah tinggal para pensiunan pendatang luar negeri yang sudah lebih dahulu paham akan keuntungan menggunakan PLTS. Karena mayoritas pemakai PLTS di Badung adalah tamu pendatang yang memiliki bisnis atau rumah di Bali.

Dalam menentukan kebijakan tentang strategi percepatan pengembangan PLTS di Bali perlu juga kita mengetahui jenis PLTS apa saja yang sudah beroperasi sampai saat ini. Hal ini bisa menjadi rujukan sektor mana yang nantinya akan A.A.G.A Pawitra: Review Perkembangan di Provinsi Bali...
187

diprioritaskan dalam memacu percepatan pemanfaatan PLTS di Bali. Berikut ini jenis PLTS yang sudah beroperasi di Bali sampai saat ini:

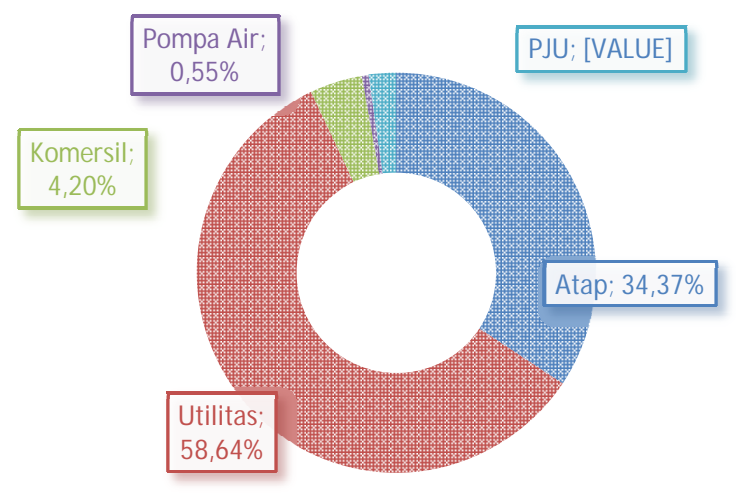

Gambar 19: Persentase jenis pengaplikasian PLTS di Bali

Diagram gambar 19 menjelaskan persentase bauran pengaplikasian PLTS yang sudah beroperasi di Bali. Bisa dilihat jenis aplikasi PLTS tertinggi adalah jenis utilitas, yang dimaksud utilitas disini adalah pembangunan PLTS ini memang ditujukan menunjang kebutuhan listrik di suatu daerah yang kekurangan listrik. Jenis PLTS utilitas yang sudah beroperasi di Bali sebesar 58,64\% atau 2.177 kWp, yang didominasi oleh PLTS terbesar di Bali, yaitu PLTS 1 MWp Karangasem dan PLTS 1 MWp Bangli. Sedangkan penggunaan terendah terdapat pada pengaplikasian PLTS untuk menggerakan pompa air, dimana jumlahnya $0,55 \%$ dari total keseluruhan PLTS di Bali. Dari berbagai jenis pengaplikasian tersebut, sistem PLTS dapat dibagi lagi menjadi tipe on-grid, off-grid, dan hibrida. Bauran tipe sistem PLTS dapat dilihat pada diagram berikut:

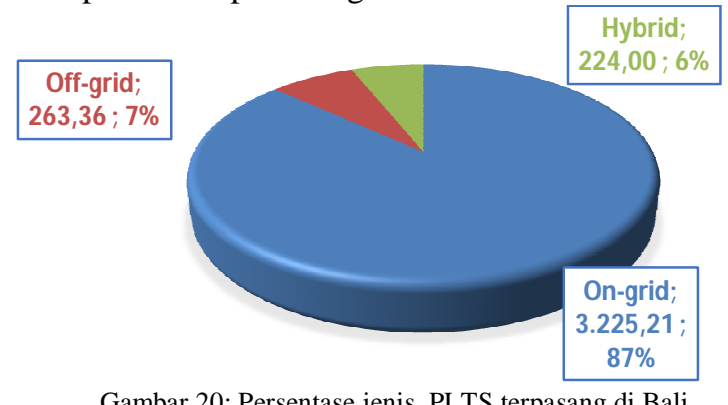

Sistem PLTS di Bali didominasi oleh sistem PLTS on-grid, dimana sistem ini merupakan sistem yang lebih terjangkau dibandingkan dengan sistem off-grid. Karena sistem on-grid tidak memerlukan penggunaan baterai pada sistemnya. Seperti yang kita ketahui pada pembangunan sistem PLTS, biaya investasi pada baterai termasuk tinggi. Jika biaya investasi kita bandingkan dengan energi yang diproduksi, maka energi terhadap biaya investasi yang dikeluarkan menjadi mahal dan tidak efisien. Sistem PLTS off-grid sebaiknya dibangun di daerah terpencil yang jaringan PLN belum bisa masuk. Maka dari itu kebijakan pemerintah pusat Permen No. 49 Tahun 2018 merupakan langkah yang baik, mengingat PLTS atap merupakan sistem yang tidak memerlukan baterai, karena

$$
\text { p-ISSN:1693 - 2951; e-ISSN: 2503-2372 }
$$


langsung disalurkan ke jaringan PLN, jika produksinya melebihi konsumsi pengguna. Tentunya hal ini dapet mengurangi biaya listrik bulanan konsumen PLN.

Sistem PLTS pada umumnya memiliki kapasitas yang berbeda-beda, begitu pula di Bali. Berbagai besaran kapasitas PLTS dapat dikategorikan menjadi beberapa kategori, PLTS berkapasitas 50-200 W yang biasa disebut Solar Home System (SHS), kapasitas 20-25 kW, 100-200 kW, 500-1000 kW. Pada diagram berikut akan menampilkan komposisi kapasitas PLTS di Bali yang sudah beroperasi sampai saat ini:

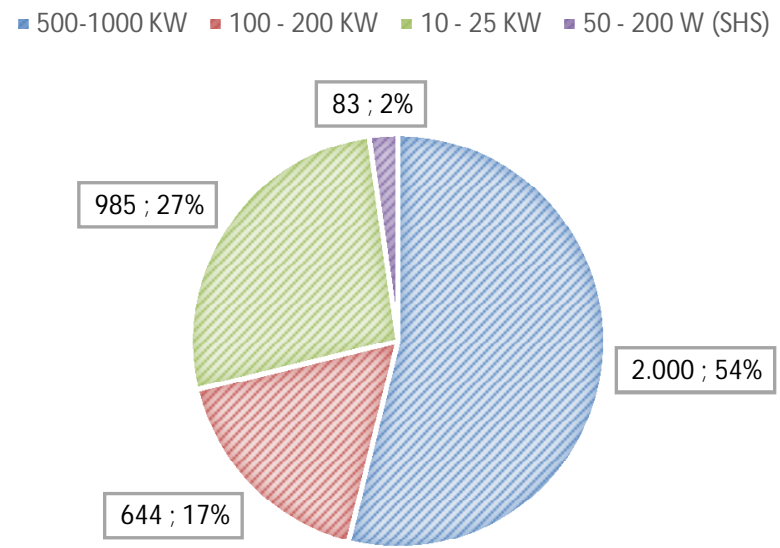

Gambar 21: Komposisi kapasitas PLTS terpasang di Bali

Berdasarkan kapasitas PLTS terpasang komposisi dapat dilihat pada gambar 21, dimana secara keseluruhan PLTS dengan kapasitas 500-1000 kW masih mendominasi dengan $54 \%$ atau $2.000 \mathrm{kWp}$ dari total kapasitas yang tersebar di Bali. Disusul PLTS kapasitas 10-25 kW dengan 27\% atau $985 \mathrm{kWp}$ yang pengaplikasiannya banyak berupa PLTS atap. Kapasitas PLTS sebesar 100-200 kW yang terinstal di Bali sebesar 644 kWp atau $17 \%$ dari keseluruhan. Kapasitas kecil atau biasa disebut Solar Home System (SHS) yang berkapasitas 50-200 $\mathrm{W}$ di Bali sudah terinstal $84 \mathrm{kWp}$ atau hanya $2 \%$ dari total kapasitas yang sudah terpasang di Bali.

\section{KeSIMPULAN}

Pembahasan pada paper ini menjelaskan sampai mana perkembangan PLTS di Bali hingga saat ini, dan kesimpulan yang diperoleh sebagai berikut:

1. Perkembangan PLTS di Bali dari tahun ke tahun cukup baik, dapat dilihat dalam 14 tahun terakhir pertumbuhan rata-rata meningkat $7,14 \%$ atau $265,18 \mathrm{kWp}$ per tahun. Pertumbuhan tertinggi terjadi pada tahun 2013, dimana saat itu Bali menerima hibah beberapa PLTS, karena Bali dijadikan percontohan pemanfaatan PLTS di daerah.

2. Kapasitas PLTS terpasang di Bali saat ini masih 3,44\% dari target yang diberikan oleh RUEN sebesar 108 MWp pada tahun 2025. Jika Provinsi Bali ingin mencapai target tersebut maka dari sekarang sampai tahun 2025, Pemangku kepentingan di Bali harus membangun PLTS dengan kapasitas total sebesar 17,38 MWp per tahun hingga tahun 2025.
3. Kapasitas PLTS terpasang di Bali tertinggi terdapat di Kabupaten Karangasem sebesar 1.106 kWp atau 29,79\% dari total kapasitas terpasang di Bali. Sedangkan kapasitas terendah terdapat di Kabupaten Jembrana dengan kapasitas terpasang sebesar $10 \mathrm{kWp}$ atau hanya $0,27 \%$.

4. Pemanfaatan PLTS di Bali digunakan dalam berbagai macam aplikasi. Berdasarkan pembahasan sebelumnya pengaplikasian PLTS terbanyak digunakan sebagai utilitas dalam menunjang penggunaan energi listrik dalam suatu daerah dengan komposisi 58,64\%. Penggunaan terendah PLTS pada aplikasi pompa air yang hanya $0,55 \%$ dari total kapasitas yang terpasang di Bali.

5. Berdasarkan jenisnya sistem PLTS yang terpasang di Bali didominasi oleh sistem PLTS on-grid dengan kapasitas terpasang $3.225,21 \mathrm{kWp}$ atau $87 \%$ dari total kapasitas PLTS di Bali. Sedangkan terendah adalah sistem PLTS hybrid dengan kapasitas terpasang 224 $\mathrm{kWp}$ atau sebesar 6\%. Sedangkan berdasarkan kategori kapasitas PLTS terpasang di Bali masih didominasi oleh PLTS berkapasitas 500-1000 kW.

\section{REFERENSI}

[1] Dewan Energi Nasional, "Rencana Strategis Dewan Energi Nasional," Jakarta, Indonesia: Kementrian Energi Sumber Daya dan Mineral (ESDM), 2015.

[2] Badan Penelitian dan Pengembangan ESDM, "Pembangkit Listrik Tenaga Surya (PLTS)," Kementrian ESDM, 2017.

[3] Peraturan Presiden Republik Indonesia No. 22 Tahun 2017 tentang Rencana Umum Energi Nasional (RUEN), 2017.

[4] Dewan Energi Nasional, "DEN Dorong Penyelesaian Raperda RUED Bali," Jakarta, Indonesia: DEN, 2019.

[5] I.N.S. Kumara, I.A.D. Giriantari, W. Ariastina, dkk., "Peta Jalan Pengembangan PLTS Atap: Menuju Bali Mandiri Energi," Bali, Indonesia: Center for Community Based Renewable Energy (CORE) \& Greenpeace Indonesia, 2019.

[6] I.N.S. Kumara, "Pembangkit Listrik Tenaga Surya Skala Rumah Tangga Urban dan Ketersediaannya di Indonesia," Bali, Indonesia: Jurnal Teknologi Elektro, 2010.

[7] ABB, "Technical Application Papers No. 10 Photovoltaic Plants," Italy: Bergamo, 2010.

[8] I.N.S Kumara, M. Ashari, Sampeallo, A.A.G.A. Pawitra, "Simulated Energy Production and Performance Ratio of $5 \mathrm{MW}$ Grid Connected Photovoltaic under Tropical Savannah Climate in Kupang Timor Island of Indonesia," Taiwan: TAETI, 2017.

[9] A.P. Damastuti, "Pembangkit Listrik Tenaga Surya," Bogor, Indonesia: Wacana ELLSPAT, 1997.

[10] Contained Energy, (2020) Case Studies. [Online]. http://www. containedenergy.com/case-studies/

[11] Prosol, (2020) Projects. [Online]. http://www.prosol.co.id/projects/

[12] M.R. Wicaksana, I.N.S. Kumara, I.A.D Giriantari, R. Irawati, "Unjuk Kerja Pembangkit Listrik Tenaga Surya Rooftop $158 \mathrm{kWp}$ pada Kantor Gubernur Bali," Bali, Indonesia: SPEKTRUM, 2019.

[13] Terregera Indonesia, (2020) Report of The Board of Directors. [Online]. https://investor.terregra.com/bod_report.html

[14] I.A. Medina, I.A.D. Giriantari, I.W. Sukerayasa, "Kajian dan Evaluasi Sistem Suplai Energi Listrik PLTS dan PLTB di Kampus Teknik Elektro Universitas Udayana Bukit Jimbaran" Bali, Indonesia: MITE, 2018

[15] Direktorat Jendral Energi Baru Terbarukan dan Konversi Energi, (2020) Indonesia Power Kini Gunakan PLTS di Area Operasi. [Online]. http://ebtke.esdm.go.id/post/2020/02/26/2486/keren.indonesia.power.ki ni.gunakan.panel.surya.di.wilayah.operasi

[16] Dinas Penanaman Modal dan Pelayanan Terpadu Satu Pintu Kabupaten Klungkung, (2019) Monev PLTS. [Online]. https://dpmptsp. klungkungkab.go.id/2019/12/10/monev-plts/ 